${ }^{1}$ Department of Internal Medicine, Diabetology and Nephrology, Medical University of Silesia, Zabrze, Poland

${ }^{2}$ Department of Internal Medicine and Diabetology, Prof. Stanisław Szyszko Independent Public Clinical Hospital No 1, Medical University of Silesia, Katowice, Poland

${ }^{3}$ Student's Scientific Association by the Department of Internal Medicine, Diabetology and Nephrology, Medical University of Silesia, Zabrze, Poland

\title{
An unusual use of personal insulin pump by a patient with type 1 diabetes on a ketogenic diet - a case report
}

\section{ABSTRACT}

In this case report we present a 28-year-old woman with type 1 diabetes mellitus on a ketogenic diet for 5 months, using a personal insulin pump in an unusual way. The patient was admitted to the Department of Internal Medicine and Diabetology due to vomiting and diarrhea that had lasted for several days. On a daily basis, she used personal insulin pump for only several hours a day (a 5-hour basal rate of 0.6 units/hour of fast-acting insulin) in order to avoid dawn phenomenon, without any prandial insulin, and she used continuous glucose monitoring for $\mathbf{2 4}$ hours a day for glycemia control. Additionally she was taking 30 units of long acting insulin analog before sleep. The patient was unwilling to change her treatment method and she was discharged from the hospital against medical advice. Due to the increase in popularity of ketogenic diet, there is a need for large studies assessing its safety and efficacy. Moreover, our case draws attention to the fact that patients can use modern technologies, which

Address for correspondence:

lek. Hanna Kwiendacz

Katedra i Klinika Chorób Wewnętrznych, Diabetologii i Nefrologii,

Śląski Uniwersytet Medyczny, Wydział Lekarski z Oddziałem

Lekarsko-Dentystycznym w Zabrzu

ul. 3 Maja 13-15, 41-800 Zabrze

Phone/fax: +48323704415

e-mail: hanna.kwiendacz@gmail.com

Translation: lek. Małgorzata Kamińska

Clinical Diabetology 2019, 8, 4, 223-226

DOI: $10.5603 /$ DK.2019.0017

Received: 26.01.2019

Accepted: 29.04.2019 are developed to improve the glycemic control, in unconventional ways. (Clin Diabetol 2019; 8, 4: 223-226)

Key words: diabetes mellitus type 1, ketogenic diet, personal insulin pump, insulin, continuous glucose monitoring

\section{Introduction}

Over the last decades, there has been a significant technological progress in the treatment of type 1 diabetes, mainly regarding new insulin preparations, continuous glucose monitoring and personal insulin pumps. However, many patients still do not achieve glycemic targets [1] and have difficulty controlling postprandial hyperglycemia, which significantly influences $\mathrm{HbA}_{1 \mathrm{c}}$ values [2]. Only $30 \%$ of adults with type 1 diabetes reach the $\mathrm{HbA}_{1 \mathrm{c}}$ target of $<7 \%$ [3]. Treatment of type 1 diabetes with intensive functional insulin therapy, including continuous subcutaneous insulin infusion (personal insulin pumps), is a recognized and effective method of treatment [4]. Clinical recommendations for dietary management of patients with diabetes indicate the need to individualize the daily amount of carbohydrates consumed in the range of $25-60 \%$ of the total daily energy requirement [5]. According to the 2019 Guidelines of Diabetes Poland, there is insufficient scientific data to determine one optimal carbohydrate dietary intake for patients with diabetes. However, it is believed that carbohydrates should account for approximately $45 \%$ of the daily energy requirement and a reduced amount of carbohydrates, i.e. $25-45 \%$ can be consumed temporarily by patients who are not 
physically active. Fats should constitute $25-40 \%$ of the daily energy intake [6]. Due to the fact that both the type and amount of carbohydrates consumed affect postprandial glycemia, patients as well as researchers are very interested in low-carbohydrates diets, including a diet with a very low amount of carbohydrates, i.e. ketogenic diet, also in patients with type 1 diabetes [7-9]. The ketogenic diet has already been used in the treatment of type 1 diabetes before the invention of insulin [10], and therefore, the history has come full circle. There is no single definition of a diet with a very low carbohydrate content; however, the most common daily amount of carbohydrates in such a diet is less than $50 \mathrm{~g}$ or less than $10 \%$ of the total daily energy intake, with increased amount of fats and proteins consumed $[3,11]$. When a ketogenic diet is used, ketosis occurs as a result of an increased production of so-called ketone bodies: acetoacetate, betahydroxybutyrate and acetone. Ketonemia reaches the maximum value of $7-8 \mathrm{mmol} / \mathrm{L}$, at blood $\mathrm{pH}$ within a normal range. When using a balanced diet, the average blood ketone concentration is $<0.3 \mathrm{mmol} / \mathrm{L}$, whereas in diabetic ketoacidosis blood ketone concentration can exceed $20 \mathrm{mmol} / \mathrm{L}$ with coexisting decrease in blood $\mathrm{pH}[12,13]$. Nowadays, patients are looking for alternative therapeutic methods, especially for various types of diets, that would improve their health. Popular websites often publish information about alleged benefits of these methods which have not been confirmed in scientific studies [14]. In recent months there has been a debate in the scientific community, caused by the publication of the paper by Lennerz et al. [15], regarding the relevance of promoting a diet with a very low carbohydrate content in patients with type 1 diabetes $[9,16]$. These authors, using an online questionnaire filled out by patients, evaluated glycemic control and adverse events, such as the occurrence of diabetic ketoacidosis, hypoglycemia, and hospitalization due to decompensation of diabetes, in children and adults with type 1 diabetes who were on a ketogenic diet [15]. The study participants were recruited from a Facebook group established in April 2014 and associating, at the time of the study, 1,900 people with type 1 diabetes on a very low carbohydrate diet (up to 30 grams/day). Finally, 493 people completed the study questionnaire, of which 316 were qualified for further observation. The results obtained indicated a good glycemic control (mean $\mathrm{HbA}_{1 \mathrm{c}}$ was $5.67 \pm 0.66 \%$ ), a low rate of hypoglycemia (in 2 patients) or ketoacidosis (in 4 patients). One can get the impression that the results of the cited work encourage the use of a ketogenic diet; nevertheless, both the authors themselves and experts commenting on the study underline the need to verify these results in well-designed, large clinical trials.
Data on the prevalence of diabetic ketoacidosis (DKA) in adults with type 1 diabetes, unlike data regarding children, are limited. Based on a recent systematic review of the literature, the incidence of DKA was estimated at $50-100$ cases per 1,000 adult patients with type 1 diabetes [17]. The data on the incidence of DKA at the level of $2 \%$ of patients presented by Lennerz et al. [15] are lower than the estimated annual risk of DKA episode in patients not using the ketogenic diet [17]; however, due to the fact that these data come from a small survey, it is not possible to conclude on that basis that the risk of developing ketoacidosis in patients on a ketogenic diet is low and that in this aspect the diet can be considered safe. Moreover, generally acknowledged contraindications to the use of the ketogenic diet, which include disorders of lipid metabolism, porphyria and pyruvate carboxylase deficiency, should be taken into account [18].

In this report we present a case of a patient with type 1 diabetes on a ketogenic diet, using a personal insulin pump in an unusual way.

\section{Case presentation}

A 28-year-old female, diagnosed with type 1 diabetes at the age of 13 , who has been treated for 5 years with personal insulin pump (Medtronic Minimed G640) with compatible continuous glucose monitoring system (CGMS) was admitted to the Department of Internal Medicine and Diabetology on July 2017 due to vomiting and diarrhea that had lasted for several days. The patient explained that she used personal insulin pump for only several hours a day, providing a 5-hour infusion of fast-acting insulin analog (insulin aspart, Novo Nordisk, 0.6 units/hour) in order to avoid dawn phenomenon between 2 a.m. and 7 a.m. Therefore, she connected the insulin pump tubing before going to sleep and disconnected it after waking up. Additionally she administered a single daily dose of basal insulin (30 units of insulin glargine U300, Sanofi Aventis) before going to sleep. She did not administer insulin boluses before meals.

In addition, for 5 months the patient has been using a ketogenic diet to avoid the need for prandial insulin. This behavior was probably caused by the lack of acceptance of the disease (the patient refused a psychologist consult). She declared the following daily intake of nutrients: $10 \mathrm{~g}$ carbohydrates, $15 \mathrm{~g}$ proteins, $120 \mathrm{~g}$ fats. On the day of admission to the Diabetology Department, the patient was in a good general condition. A physical examination did not reveal any abnormal findings, except for dryness of the oral mucosa. The BMI was $20.5 \mathrm{~kg} / \mathrm{m}^{2}$ (body weight $62 \mathrm{~kg}$, height $174 \mathrm{~cm}$ ). The only abnormal results of the laboratory tests were 
Table 1. Blood glucose levels during hospitalization $[\mathrm{mg} / \mathrm{dL}]$

\begin{tabular}{lcccccc}
\hline Date|Time & $\mathbf{3 : 0 0}$ & $\mathbf{8 : 0 0}$ & $\mathbf{1 2 : 0 0}$ & $\mathbf{1 6 : 0 0}$ & $\mathbf{2 1 : 0 0}$ & $\mathbf{2 4 : 0 0}$ \\
\hline 14.07 .2017 & - & - & - & 147 & 113 & 87 \\
15.07 .2017 & 72 & 79 & 106 & 75 & 82 & 107 \\
16.07 .2017 & 107 & 116 & 100 & 110 & 104 & 85 \\
17.07 .2017 & 71 & 100 & -144 & - & - & - \\
18.07 .2017 & - & 80 & - & & & - \\
\hline
\end{tabular}

the increased concentration of betahydroxybutyrate in the venous blood $(6 \mathrm{mmol} / \mathrm{L})$, with normal blood $\mathrm{pH}$, and ketonuria $(++++)$. Blood glucose at admission was $147 \mathrm{mg} / \mathrm{dL}$. During the hospitalization glycemic values were within normal range, which is presented in Table 1. The results of other laboratory tests (complete blood count, serum aminotransferases [AST and ALT] and lipid concentration, venous blood gasometry) did not show significant deviations from the reference values.

After intravenous rehydration (the patient did not consent to the administration of glucose either orally or intravenously) and treatment with proton pump inhibitor administered intravenously, dyspeptic symptoms resolved and the patient was discharged on the fourth day of hospitalization at her own request, against medical advice. During the hospitalization, the patient did not agree to diet modification or administration of prandial insulin.

According to the patient, after she had been diagnosed with diabetes her mean $\mathrm{HbA}_{1 \mathrm{c}}$ values oscillated around $7 \%$. The introduction of the ketogenic diet resulted in a reduction in $\mathrm{HbA}_{1 \mathrm{c}}$ value from $6.4 \%$ to $5.4 \%$, and the blood glucose self-monitoring values remained in the range of $60-90 \mathrm{mg} / \mathrm{dL}$. Moreover, she did not observe body weight reduction while being on the diet. The patient monitored her blood ketone concentration on a daily basis using an Optium Xido Abbott Diabetes glucose meter, thus assessing the state of ketosis. While on a ketogenic diet, the patient had never had symptoms like the one observed just before hospitalization. She claimed that the way she use a personal insulin pump in combination with basal insulin injected with a pen and a ketogenic diet has been accepted by her diabetologist; however, she did not have any medical documentation confirming this information. It is also worth noting that the amount of fat consumed by the patient in proportion to the other nutrients (about $90 \%$ of the total daily caloric supply) is not in accordance with any recommendations of diabetic or dietary associations. Average daily blood glucose values of 60-90 mg/dL, which in the long-term perspective may have a negative effect on neurocyte function, also raise concern [19].
It should be emphasized that due to the lack of randomized, prospective trials assessing the safety of the ketogenic diet, its impact on individual metabolic pathways, the body composition by percent of mass or long-term systemic effects is not known. However, it has been proven that excessive protein supply may adversely affect kidney function in people with reduced renal filtration, and patients with type 1 diabetes are at particularly high risk of this complication [20,21]. In addition, high-fat products contribute to the progression of atherosclerotic lesions and increased visceral fat, which increases insulin resistance [22].

Taking into account lack of the patient's consent to psychological consultation, strict carbohydrate restriction and BMI values at the lower limit of the normal range, anorexia-related eating disorders should be considered. It is also important that the patient, although using insulin reservoirs and infusion sets for insulin administration for only a few hours daily, is subject to the same reimbursement principles as the patients who use them 24 hours a day, which is not negligible, given the reimbursement-related costs incurred by the payer.

\section{Summary}

The presented clinical case shows that the patients can use the recommended forms of therapy in their own way, not necessarily consistent with the current principles of the treatment of type 1 diabetes [4, 5]. According to our knowledge, this is the first report describing the unconventional use of a personal insulin pump in the treatment of type 1 diabetes, where the pump therapy, used only to prevent the dawn phenomenon in the early morning hours, is combined with the single daily injections of a long-acting insulin analog, while eliminating prandial insulin boluses through the use of a ketogenic diet. Modern technologies developed to improve blood glucose monitoring and insulin therapy certainly facilitate obtaining the desired glycemic control by patients using different diets; however, it should be noted that the presented diet does not meet the principles of healthy nutrition in type 1 diabetes, so it should not be accepted by a health care provider. The case of the described patient 
points out the need to carry out large trials assessing short- and long-term safety, but also the effectiveness of the ketogenic diet, which patients use more and more often. It also indicates that modern tools, in this case an insulin pump, can be used by patients in an unconventional way.

\section{Conflict of interests}

The authors declare no conflict of interest.

\section{REFERENCES}

1. McKnight JA, Wild SH, Lamb MJE, et al. Glycaemic control of Type 1 diabetes in clinical practice early in the 21st century: an international comparison. Diabet Med. 2015; 32(8): 1036-1050, doi: 10.1111/dme.12676, indexed in Pubmed: 25510978.

2. Rohlfing $\mathrm{CL}$, Wiedmeyer $\mathrm{HM}$, Little RR, et al. Defining the relationship between plasma glucose and $\mathrm{HbA}(1 \mathrm{c})$ : analysis of glucose profiles and $\mathrm{HbA}(1 \mathrm{c})$ in the Diabetes Control and Complications Trial. Diabetes Care. 2002; 25(2): 275-278, indexed in Pubmed: 11815495.

3. Miller KM, Foster NC, Beck RW, et al. T1D Exchange Clinic Network. Current state of type 1 diabetes treatment in the U.S.: updated data from the T1D Exchange clinic registry. Diabetes Care. 2015; 38(6): 971-978, doi: 10.2337/dc15-0078, indexed in Pubmed: 25998289.

4. Pickup J, Keen H. Continuous subcutaneous insulin infusion at 25 years: evidence base for the expanding use of insulin pump therapy in type 1 diabetes. Diabetes Care. 2002; 25(3): 593-598, indexed in Pubmed: 11874953.

5. 2. Classification and Diagnosis of Diabetes:Standards of Medical Care in Diabetes - 2018. Diabetes Care. 2017; 41(Supplement 1): S13-S27, doi: $10.2337 / \mathrm{dc} 18-\mathrm{s} 002$.

6. 2019 Guidelines on the management of diabetic patients A position of Diabetes Poland. Clin Diabetol. 2019; 8(1): 1-95, doi: 10.5603/DK.2019.0001

7. Sheard NF, Clark NG, Brand-Miller JC, et al. Dietary carbohydrate (amount and type) in the prevention and management of diabetes: a statement by the american diabetes association. Diabetes Care. 2004; 27(9): 2266-2271, indexed in Pubmed: 15333500.

8. Bell KJ, King BR, Shafat $A$, et al. The relationship between carbohydrate and the mealtime insulin dose in type 1 diabetes. J Diabetes Complications. 2015; 29(8): 1323-1329, doi: 10.1016/j. jdiacomp.2015.08.014, indexed in Pubmed: 26422396.

9. Bistrian BR. Two Types of Very Low-Carbohydrate Diets. Pediatrics. 2018; 142(2), doi: 10.1542/peds.2018-1536A, indexed in Pubmed: 30065006

10. Mazur A. Why were "starvation diets" promoted for diabetes in the pre-insulin period? Nutr J. 2011; 10: 23, doi: 10.1186/14752891-10-23, indexed in Pubmed: 21396115.

11. Paoli A, Rubini A, Volek JS, et al. Beyond weight loss: a review of the therapeutic uses of very-low-carbohydrate (ketogenic) diets.
Eur J Clin Nutr. 2013; 67(8): 789-796, doi: 10.1038/ejcn.2013.116, indexed in Pubmed: 23801097.

12. Paoli A, Bosco G, Camporesi EM, et al. Ketosis, ketogenic diet and food intake control: a complex relationship. Front Psychol. 2015; 6: 27, doi: 10.3389/fpsyg.2015.00027, indexed in Pubmed: 25698989.

13. Veech RL. The therapeutic implications of ketone bodies: the effects of ketone bodies in pathological conditions: ketosis, ketogenic diet, redox states, insulin resistance, and mitochondrial metabolism. Prostaglandins Leukot Essent Fatty Acids. 2004; 70(3): 309-319, doi: 10.1016/j.plefa.2003.09.007, indexed in Pubmed: 14769489.

14. o'Connor A. How a low-carb diet might aid people with type 1 diabetes. New York Times, 2018: Maj 7, Avaiable at: https:// wwwnytimescom/2018/05/07/well/live/low-carb-diet-type1-diabeteshtml.

15. Lennerz BS, Barton A, Bernstein RK, et al. Management of Type 1 Diabetes With a Very Low-Carbohydrate Diet. Pediatrics. 2018; 141(6), doi: 10.1542/peds.2017-3349, indexed in Pubmed: 29735574.

16. Mayer-Davis EJ, Laffel LM, Buse JB. Management of type 1 diabetes with a very low-carbohydrate diet: a word of caution. Pediatrics. 2018; 142(2), doi: 10.1542/peds.2018-1536B, indexed in Pubmed: 30065007.

17. Farsani SF, Brodovicz K, Soleymanlou N, et al. Incidence and prevalence of diabetic ketoacidosis (DKA) among adults with type 1 diabetes mellitus (T1D): a systematic literature review. BMJ Open. 2017; 7(7): e016587, doi: 10.1136/bmjopen-2017-016587, indexed in Pubmed: 28765134

18. Gupta L, Khandelwal D, Kalra S, et al. Ketogenic diet in endocrine disorders: Current perspectives. J Postgrad Med. 2017; 63(4): 242-251, doi: 10.4103/jpgm.JPGM_16_17, indexed in Pubmed: 29022562.

19. Languren G, Montiel T, Julio-Amilpas A, et al. Neuronal damage and cognitive impairment associated with hypoglycemia: An integrated view. Neurochem Int. 2013; 63(4): 331-343, doi: 10.1016/j.neuint.2013.06.018, indexed in Pubmed: 23876631.

20. Knight EL, Stampfer MJ, Hankinson SE, et al. The impact of protein intake on renal function decline in women with normal renal function or mild renal insufficiency. Ann Intern Med. 2003; 138(6): 460-467, indexed in Pubmed: 12639078.

21. Ko GJ, Obi $Y$, Tortorici AR, et al. Dietary protein intake and chronic kidney disease. Curr Opin Clin Nutr Metab Care. 2017; 20(1): 77-85, doi: 10.1097/MC0.0000000000000342, indexed in Pubmed: 27801685.

22. von Frankenberg AD, Marina A, Song $X$, et al. A high-fat, high-saturated fat diet decreases insulin sensitivity without changing intraabdominal fat in weight-stable overweight and obese adults. Eur J Nutr. 2017; 56(1): 431-443, doi: 10.1007/s00394-015-1108-6, indexed in Pubmed: 26615402. 